\section{EP63 THE TAPAS STUDY: THROMBECTOMY ASPIRATION POST-MARKET STUDY IN ACUTE STROKE}

${ }^{1} \mathrm{~F}$ Ballenilla Marco, ${ }^{2} \mathrm{M}$ Espinosa, ${ }^{2} \mathrm{~J}$ Zamarro, ${ }^{3} \mathrm{~J}$ Masso, ${ }^{3} \mathrm{E}$ Garmendia, ${ }^{4} \mathrm{~J}$ Pumar, ${ }^{3} \mathrm{~J}$ Larrea ${ }^{4} \mathrm{~A}$ Mosqueira. ${ }^{1}$ Department of Neuroradiology, Hospital Universitario 12 de Octubre, Madrid; ${ }^{2}$ Hospital Virgen de la Arrixaca, Murcia; ${ }^{3}$ Centro Hospitalario Universitario Donostia, San Sebastian; ${ }^{4}$ Hospital Universitario de Santiago de Compostela, Santiago de Compostela Spain

\subsection{6/neurintsurg-2021-ESMINT.62}

Introduction The Q Aspiration catheter design has shown increased aspiration force in bench studies ${ }^{1}$. The objective of this first clinical study was to assess safety and performance of the $\mathrm{Q}^{\mathrm{TM}}$ Catheter in a real-world setting. The study was a multi-center, observational, post market study utilizing the $\mathrm{Q}$ Catheter as first-line therapy during mechanical thrombectomy in Spain.

Methods Patients with AIS treated with Q as first line therapy between March 2019 and January 2020 were identified at four centers in Spain. Inclusion criteria included 18-85 years of age, anterior or posterior LVO, ASPECTs 6-10 and within 8 hours of onset/last known well. Baseline demographics, procedural data, post procedure neuroimaging, and clinical outcomes were reported. A follow up visit was conducted to assess mRS.

Results There were 45 patients included. Average age at presentation was 72.4 and $53.3 \%$ were male. Thrombolytic therapy was given in $46.7 \%(21 / 45)$ and NIHSS was 14.4 (range 1-26). Final mTICI $2 \mathrm{~b}-3$ was achieved in $93 \%$ of patients (42/45). First pass success of mTICI $2 b-3$ with only a Q Catheter was achieved in 49\% (21/43), increasing to 56\% (24/43) when a stent retriever was used as an anchor. Overall successful revascularization using the Q Catheter was 77\% (33/43). ENT was 2\% (1), sICH rate was 2\% (1), and mortality during the study period was $13 \%$ (6). At follow-up, $55.5 \%$ of subjects had a mRS of $0-2$.

Conclusion The Q Catheter showed good deliverability and revascularization rates in this real-world setting with no safety concerns.

\section{REFERENCE}

1. Long TD, Kallmes DF, Hanel R, Shigematsu T, Halaszyn AM, Wolter J, Berenstein A. Novel aspiration catheter design for acute stroke thrombectomy. I Neurointerv Surg 2019 Feb;11(2):190-195.

Disclosure Consultant MIVI Neuroscience, Inc.

\section{EP64 SYSTEMATIC REVIEW AND ANALYSIS OF PRE-CLINICAL SIDE-BY-SIDE COMPARISONS OF EMBOTRAP VERSUS SOLITAIRE PERFORMANCE}

${ }^{1} \mathrm{M}$ Mirza, ${ }^{1} \mathrm{R}$ McCarthy, ${ }^{2} \mathrm{M}$ Gilvarry. ${ }^{1}$ Neuro Thromboembolic Initiative; ${ }^{2}$ Cerenovus, Galway, Ireland

\subsection{6/neurintsurg-2021-ESMINT.63}

Introduction The first pass effect (FPE) has gained acceptance as the new measure of success for mechanical thrombectomy. Lacking clinical trials that compare devices, in-vitro studies may be useful to investigate the impact of device designs to FPE.

Aim of the Study To systematically compare EmboTrap performance using side-by-side generated in-vitro comparative studies
Methods A systematic review of literature for pre-clinical data containing in-vitro thrombectomies was performed in Pubmed. Articles were included if multiple devices including EmboTrap were used in the same models, techniques, and blood clot analogs. Individualized data were extracted, and a pooled analysis was performed. Comparisons of recanalization success between stent-retrievers and different clot types were performed using two-way analysis of variance (ANOVA) and a two-sample t-test with Tukey's honestly significance.

Results An initial search revealed 277 articles, 4 articles met the inclusion criteria. Only EmboTrap and Solitaire devices were consistently used in all 4 articles, limiting comparisons to only these two devices. Three articles described outcomes as first-pass complete clot removal, while one article allowed up to 3 passes, for a total of 210 thrombectomy attempts. Of the three clot types studied, friable and tough clots were recanalized less effectively than standard clots $(p<0.01)$, but not different from each other $(p>0.05)$. EmboTrap had better recanalization outcomes than Solitaire $(\mathrm{p}<0.01)$, particularly observed for friable $(p<0.05)$ and standard $(p<0.05)$ clots, but not for tough clots $(\mathrm{p}>0.05)$.

Conclusions Pre-clinical data, particularly from combined independent studies, can provide insightful comparisons between device designs.

\section{REFERENCES}

1. Machi $P$, Jourdan F, Ambard D, et al. Experimental evaluation of stent retrievers mechanical properties and effectiveness. J Neurointerv Surg 2017 Mar;9(3):257263.

2. Chueh JY, Marosfoi MG, Brooks OW, et al. Novel distal emboli protection technology: the EmboTrap. Interv Neurol 2017 Oct;6(3-4):268-276.

3. Kaneko N, Komuro $\mathrm{Y}$, Yokota $\mathrm{H}$, et al. Stent retrievers with segmented design improve the efficacy of thrombectomy in tortuous vessels. I Neurointerv Surg 2019 Feb;11(2):119-122.

4. Soize S, Pierot L, Mirza M, et al. Fast stent retrieval improves recanalization rates of thrombectomy: experimental study on different thrombi. AJNR Am J Neuroradiol 2020 Jun:41(6):1049-1053.

Disclosure MM, RM, and MG are employees of Cerenovus.

\section{EP65 MECHANICAL THROMBECTOMIES, INITIAL EXPERIENCES FROM KOSOVO CASE SERIES PRESENTATION}

${ }^{1,2} \mathrm{~B}$ Gjikolli, ${ }^{3} \mathrm{~V}$ Kalousek, ${ }^{3} \mathrm{~B}$ Culo, ${ }^{1} \mathrm{M}$ Murati, ${ }^{1,4} \mathrm{I}$ Bejta, ${ }^{5} \mathrm{~J}$ Shatri, ${ }^{6} \mathrm{~N}$ Shala, ${ }^{5} \mathrm{~K}$ Dedushi, ${ }^{6} \mathrm{~F}$ Jashari, ${ }^{5} \mathrm{~F}$ Pasha, ${ }^{6} \mathrm{E}$ Komoni, ${ }^{6} \mathrm{D}$ Boshnjaku, ${ }^{6} \mathrm{~B}$ Myftiu, ${ }^{7} \mathrm{~L}$ Jaha, ${ }^{8} \mathrm{~A}$ Kuçi, ${ }^{5} \mathrm{R}$ Miftari, ${ }^{6} \mathrm{~V}$ Govori, ${ }^{9} \mathrm{D}$ Bulja, ${ }^{9} \mathrm{~S}$ Vegar. ${ }^{1}$ Radiology Clinic, University Clinical Centre of Kosova, Prishtine, Republic of Kosovo; ${ }^{2}$ Radiology, AAB College, Prishtinë, Republic of Kosovo, Bosnia and Herzegovina; ${ }^{3}$ Radiology, KBCSM - Klinički bolnički centar Sestre milosrdnice, Zagreb, Croatia; ${ }^{4}$ Radiology, AAB College, Prishtinë, Republic of Kosovo; ${ }^{5}$ Radiology Clinic ${ }^{6}$ Neurology Clinic; ${ }^{7}$ Vascular surgery Clinic, University Clinical Centre of Kosova, Prishtine, Republic of Kosovo; ${ }^{8}$ Dentistry, AAB College, Prishtinë, Republic of Kosovo, Albania ${ }^{9}$ Radiology Clinic, Klinicki Centar Univerziteta Sarajevo, Sarajevo, Bosnia and Herzegovina

\subsection{6/neurintsurg-2021-ESMINT.64}

Background Recent thrombectomy trials support endovascular therapy (EVT) as the standard of care in appropriately selected patients with acute ischemic stroke (AIS). We, herein, report the series of five mechanical thrombectomy cases that were performed for the first time ever in Kosovo, starting from 18th of March 2020 and ongoing.

Case Presentation Patients, who required mechanical thrombectomy from our Radiology clinic in UCCK were in between 21 to 70 years old, three females and two males. Male patients 
had left side ACM occluded, while female patients had the left ACM occlusion, with a sudden onset of right/left hemiparesis, right gaze preference and aphasia.

The first case (58 years male) we performed mechanical thrombectomy with aspiration. CT angiography revealed acute left ACM occlusion, $15 \mathrm{~mm}$ M1 thrombus in the left ACM, NIHSS score 13 before the procedure (19.45 hours) and after the procedure 7 points NIHSS (00.45 hours). All patients underwent MRI and MRA examination next day was performed presenting patent recanalized arteries.

Intervention Following confirmation of lesion amenable to mechanical thrombectomy, patients underwent successful complete reperfusion TICI (3) revascularization of ACM territories, four of which using the stent retriever.

Conclusion Endovascular treatment has proven to be safe and efficacious for AIS. Our patients recovered and were discharged within 7-11 days after ictus.mRS after 90 days 0 at two (male) patients,mRS 1 at two patients and one patient is mRS 3 .

These case series demonstrate the clinical efficacy, safety, and favorable clinical outcome of first mechanical thrombectomies performed in Kosovo.

\section{REFERENCES}

1. Heider D, Simgen A, Wagenpfeil G, et al. Why we fail: mechanisms and co-factors of unsuccessful thrombectomy in acute ischemic stroke. Neurological Sciences 2020.

2. Meyer L, Alexandrou M, Leischner H, Flottmann F, Deb-Chatterji M, Abdullayev $\mathrm{N}$, et al. Mechanical thrombectomy in nonagenarians with acute ischemic stroke. Journal of Neurolnterventional Surgery 2019;11(11):1091-1094.

3. Lansberg M, Mlynash M, Hamilton S, Yeatts S, Christensen S, Kemp S, et al. Association of thrombectomy with stroke outcomes among patient subgroups. JAMA Neurology 2019;76(4):447.

Disclosure Nothing to disclose 